\title{
KALKINAMAMIŞ YÖRELER İÇIN İNOVATIF YOL: A.B.D. FIRSAT BÖLGESI VERGI TEŞVIK YATIRIM YASASI
} Mustafa Şeref AKIN1

ÖZ

Kalkınamamış yörelere teşvikte inovatif bir yol Amerika Birleşik Devletleri’nde 2017'de ilk kez yasası çıkan ve 2019'da revizyon edilen “firsat bölgesi” (opportunity zone) vergi teşvik yatırım yasasıdır. Bu makalede A.B.D.’nin yürürlüğe koyduğu ve ilerlettiği yasanın içeriği, eleştirileri ve Türkiye'dekiyle karşılaştırması incelendikten sonra, Türkiye'ye olası uygulamadaki zorluklar tartışılmaktadır. Teşvik sisteminde vergide 3 avantaj sağlanmaktadır: Vergi öteleme (mevcut vergiyi 7 yıl sonra ödeme); mevcut vergide indirim ( 5 yıl sonra $\% 10$ ve 7 yıl sonra $\% 15$ indirim) ve firsat bölgesine yatırımdan sonra vergiden muafiyettir (10 yıl boyunca firsat bölgelerine yatırımlardan elde edilecek gelirler vergiden muaftır). Türkiye'deki teşviklere göre farkları sıralanırsa: Türkiye'deki teşvikler iller bazındadır. Bir il ya tamamıyla teşvik bölgesindedir ya da değildir. Türkiye'deki uygulamada yatırım yapıldığında vergi teşvik imkânı sağlanmaktadır. Mevcut olan bir vergi yükümlülüğüne yönelik bir teşvik yoktur. Türkiye'de teşvik bölgesindeki teşvikten faydalanmak için aktif olarak yatırım yapılması gerekmektedir. Türkiye'de bu bir fon üzerinden pasif yatırımcı olarak gerçekleştirilememektedir. Türkiye'de teşvik kapsamına giren illerde her ekonomik faaliyet vergi indirimine konu olmamaktadır. Ekonomik faaliyetin ilde belli noktalarda (organize sanayi bölgesinde) ve belli sektörlerde (tarım) olmalıdır. A.B.D.’deki uygulamada mahalle/yöre bazlıdır. Fonun yatırımının en az \%90'nunun fırsat bölgesinde olması şartıyla teşviklerden pasif yatırımcı olarak faydalanılmaktadır. Konu ve miktar sıralaması getirmemiştir. Bu aşamada bütün hedef sermayeyi ve sermayedarı firsat bölgesine sokmaktır.

Anahtar Kelimeler: firsat bölgesi, teşvik şeması, vergi öteleme

Jel Kodları: H2

${ }^{1}$ Prof. Dr., Erzincan Binali Ylldırım Üniversitesi, mustafa.akin@erzincan.edu.tr ORCID: 0000-0002-1850-9118 


\title{
INNOVATIVE WAY FOR UNDEVELOPED REGIONS: U.S.A. OPPORTUNITY REGION TAX INCENTIVE INVESTMENT LAW
}

\begin{abstract}
An innovative way to promote underdeveloped regions is the opportunity zone tax incentive investment law, which was introduced in the United States for the first time in 2017 and revised in 2019. This article discusses content, advancement, criticisms and comparisons with Turkish incentive and practical difficulties application of the new law in Turkey. There are three advantages in taxation in the incentive system: tax deferral (pay current tax after 7 years); tax relief (10\% after 5 years and 15\% discount after 7 years) and exemption from tax (taxable from income from investments in opportunity zones for 10 years). The current Turkish incentive work at this schema: Turkish incentives are based on provinces. A province is either entirely in the incentive zone or not. Tax incentives are provided in Turkey if there is an actual investment to the city. There is no incentive for existing tax liability. In order to take advantage from incentives in opoortunity zones in Turkey there should be an actual investment. This can not be carried out as a passive investor funds in Turkey. Every economic activity in opportunity zones is not subject to tax deduction. Economic activity should be at specific points in the province (organized industrial zone) and in specific sectors (agriculture). In the United States, it is based on neighborhood or region. Incentives are utilized as passive investors in the condition that at least $90 \%$ of the fund's investment is in the opportunity zone. The law did not bring any restrictions in terms of investment subjects and quantity. At this stage, the main aim is to attract the capital and the investors to the opportunity zone.
\end{abstract}

Keywords: Opportunity zone, incentive schema, tax deferral

Jel Codes: $\mathrm{H} 2$ 


\section{GİRİs}

Bölgesel teşvikler, ülke ortalama gelişmişlik seviyesinden geri kalmış, bir bölgesine özel sektörün yatırım yapması için verilen mali (vergisel indirim ve kredi sağlama) ve mali olmayan (arazi) teşviklerdir (Ünsaldı, 2006; Özker ve Biniş, 2010; Dağ ve Çelik, 2018). Türkiye'nin geri kalmış illerini kalkındırmak amacıyla yatırım teşvik uygulamaları 1913 yılına kadar uzanmaktadır (Yayar ve Demir, 2015). Modern yatırım teşvik kanunu 1962 'de planlı dönemle gerçekleşmiştir (Gülmez ve Noyan, 2011). Uzun yıllar bölgesel önceliklere dayalı sistemler içermiş olmasına rağmen, bölgelerarası farklı1ıkları gidermede başarılı olmadığı görülmektedir (Çiloğlu, 2000). Teşvikte inovatif bir yol Amerika Birleşik Devletleri'nde 2017'de ilk kez yasası çıkan ve 2019'da revizyon edilen "fırsat bölgesi” (opportunity zone) vergi teşvik yatırım yasasıdır. Bu makalede A.B.D.’nin yürürlüğe koyduğu ve ilerlettiği yasanın içeriğini, eleştirilerini ve Türkiye'deki teşvik yasalarıyla karşılaştırmasını incelendikten sonra, Türkiye'ye olası uygulamadaki zorluklar tartışılmaktadır.

\section{FIRSAT BÖLGESI KANUNU VE İÇERIĞİ NEDIR?}

Fırsat bölgesi (opportunity zones) Amerika Birleşik Devletleri tarihinin en büyük ekonomik gelişme çabalarından biridir ve fakir insanların yaşadıkları mahallelere özel sermaye yatırımı sağlama imkânı sunmaktadır (Katz, 2019; Tankersley, 2019; Nitti, 2019). A.B.D. firsat bölgesi kanunundan önce birçok teşvikler uygulanmış ama arzu edilen seviyede fakirliğin azaltılması başarılamamıştır. $\mathrm{Bu}$ yasanın odak noktası üretici firmalardan veya kamu yatırımlarından çok sermayedar kesimi doğrudan veya mali yatırım yapmaları için teşvik etmektir.

Teşvik sistemine göre yatırımcıların nitelikli bir fırsat bölgesine sermaye yatırması durumunda mevcut gayrimenkul veya menkul satışından elde edilen sermaye-kazanç vergisi ödemesi ötelenmektedir (O’brien, 2019).

\subsection{Fursat Bölgesi Kanunu Nasıl Çalışır?}

Yeni vergi indirimi, diğer federal vergi teşviklerinden farklılık göstermektedir. İlk olarak, pazar odaklıdır; teşvikleri dağıtmak için bir federal kurumlar kullanılmaz. Bireysel, kurumsal ve profesyonel yatırımcıların kararları etkilidir. İkincisi yatırım konusu tamamen serbest bırakılmıştır. Düşük gelirlere yönelik konut gibi nispeten dar amaçlar ile sınırlandırılmak yerine, her çeşit projeyi kapsamaktadır (konut, ticari, endüstriyel, altyapı). Sadece yatırımın coğrafi olarak firsat bölgesinde olması yeterlidir. Üçüncüsü, yatırımcıların iş yaratma veya yerel finansal eşleşmeler gibi belirli bir sonuca ulaşması gerekmez. Dahası, yatırımcılar bir teşvik karşılığında ne kadar yatırım yapacaklarına dair herhangi bir sınırlama ile karşı karşıya değillerdir (Katz, 2019). Dördüncüsü, devlet sübvansiyonlu kredi ve arazi araçlarından ziyade öz sermaye yatırımlarına dayanmaktadır. Teşvik yasasıyla ayrılmış kaynakları geleneksel hükümet programları aracılığıyla dağıtmak yerine, özel sektör kararıyla kaynakları dağıtmaktadır. Beşincisi, teşvikten faydalanabilmek için uzun vadeli yatırım yapılması gereklidir.

\subsection{Fursat Bölgesinin Öncü Etkileri}

Toplam 8.700 yöre ve 35 milyon ikametgah edeni kapsamaktadır (O’brien, 2018). Firsat Bölgesi teşviki, finansörler, eyalet ve bölgesel yönetime, yerel yatırımcılar ve topluluklar için önemli 
bir fayda sağladığından emin olmak için birlikte çalışmaları için büyük bir itici güç sağlamaktadır (Katz, 2019). 2017'de ilk kanunu geçtiğinden beri, gayrimenkul fiyatları \%20 yükselmiş durumdadır. Bu yükseliş yeni yatırımları teşvik etmektedir. 2017-19 arasında 25 milyar USD yatırım gerçekleşmiştir (Thomas, 2019). 10 yıl içinde sadece gayrimenkul yatırım ortaklıkları (REIT) üzerinden 1 trilyon dolarlık yatırıma ulaşması beklenmektedir. Programın başarısı daha tam belirginleşmemişse de, ilk işaretler oldukça olumludur (Looney, 2018). 2017'deki eksiklileri giderilerek 2019'da yasada revizyona gidilmiştir. Örneğin, 2019 versiyonunda işletmenin bir bölgede yeterince faaliyet gösterdiğini nasıl kanıtlayabileceği konusunda daha fazla netlik sağlanmaktadır (Davison ve Buhayar, 2019).

\subsection{Firsat Bölgesine Yatırımlarında Vergisel Avantajlar}

İki türlü avantaj sağlanmaktadır: mevcut sermaye kazanç vergisinin ötelenerek azaltılması ve firsat bölgesine yatırımdan elde edilecek kazançlarına vergi muafiyeti getirilmesi.

Fırsat bölgesine yatırmadan evvel ki elde edilen kazançtan doğacak vergi yükümlülüğü, bölgede yatırımın devam etmesiyle azaltılmaktadır (i) en az beş yıl boyunca firsat bölgesine yatırım yapan mükellefler mevcut sermaye kazancı vergilerinde yüzde 10'luk bir indirim alırlar; yatırımların en az yedi yıl tutulması ile yüzde 5'lik ek bir azalma sağlamaktadır (ii) 10 yıl boyunca vergi matrahındaki geliri tuttuklarında ise, firsat bölgesine yatırımdan doğan herhangi bir sermaye kazancı vergisi ödemesi gerekmemektedir. 10 y1ldan fazla tutulduğunda da vergi muafiyeti sürmektedir (iii) (Nitti, 2019).

Vergide 3 avantaj sağlanmaktadır:

- Mevcut verginin ötelenmesi: 7 y1l sonra ödeme

- Mevcut verginin indirimi: 5 y1l sonra $\% 10$ ve 7 y1l sonra $\% 15$ indirim

- Vergiden muafiyeti: 10 y1l boyunca firsat bölgelerine yatırımlardan elde edilecek gelirlerden vergi muafiyeti (Investreal, 2019).

\subsection{Fursat Bölgesinin Seçimi}

Yasa, eyaletlere düşük gelirli nüfuslu "fırsat bölgeleri” seçmeleri yönünden rol vermektedir. Nisan 2018'den bu yana, 50 eyaletteki her vali, Columbia Bölgesi (başkent) ve Porto Riko dahil olmak üzere, genel fakirlik (mahallede yaşayanlar A.B.D: ortalamasının \%20 altındadır), yüksek işsizlik, çocuk fakirliği kriterlerine dayalı olarak 8,700'den fazla fırsat bölgesi belirlemiştir (Perlman, 2019).

Yasa, şehirlerin veya yerel bölgelerin yönetiminin rolü hakkında herhangi bir rehberlik sağlamamaktadır. Yine de en geniş anlamdaki şehirler - yerel yönetimler, özel ve sivil kuruluşlar, topluluk ağları - fırsat bölgeleri için kapsayıcı, sürdürülebilir ve gerçekten dönüştürücü bir büyüme sağlayacaksa, anlamlı önlemler almaları gerekecektir(Katz, 2019).

\subsection{Fırsat Bölgesinin Örnekle Açıklanması}

Ekonomik avantaj sistemin nasıl çalıştığı iki örnekle açıklansın. Birinci örnekte, bir vergi mükellefi 3 yıl önce 150.000TL'ye bir gayrimenkul almakta ve bu yıl 200.000 TL'ye satmaktadır. Bu satış farkından dolayı 50.000 TL gelirler vergisi matrahı doğmaktadır. Eğer mükellef \%20’lik bir dilim içerisindeyse, 10,000 TL'lik vergi ödemektedir. 50.000 TL'yi firsat bölgesine en az 5 yıllığına yatırım yapıldığında 5 yıl sonra vergi ödenmektedir. Ödeyeceği vergiden \%10 düşürülmektedir. Eğer 7 yıla 
taşırsa \%15 daha az ödenmektedir. Enflasyonun yıpratma payı da düşünülürse ciddi bir indirim sağlanmaktadır. Ayrıca 10 yıl boyunca firsat bölgesinde yatırım tutulduğunda elde edilen yeni gelirden herhangi bir vergi ödenmemektedir.

İkinci örnekte daha kapsamlı olarak rakamlarla ve oranlarla açılamaktadır. Şekil 1'de 10 milyon USD’lık sermaye kazancını firsat bölgesini içeren ve içermeyen iki benzer uzun dönemli fona konduğu varsayılmaktadır. Her iki fonda da vergi öncesi yıllık getiri \%7 varsayılmaktadır. 15 yıl sonunda iki fonun getirisi karşılaştırılmaktadır. Fırsat bölgesi fonuna yatırıldığında herhangi bir vergi ödenmesine uğramadan tüm kazanç fona aktarılmaktadır. Hâlbuki, vergi ödeyen kişi 7.620.000 ile fona başlamaktadır. 15 yıl sonra firsat bölgesi fonuna yatırım yapan ve teşviklerden faydalananın 25.567.315 USD’1 olmakta ve \%6.16 getiri sağlamaktadır. Fırsat bölgesi fonuna girmeyen ise, 17.833.711 USD kazanmakta ve \%3.13 getiri de kalmaktadır.

\section{Şekil-1: 10 Milyon USD Sermaye Kazancı}

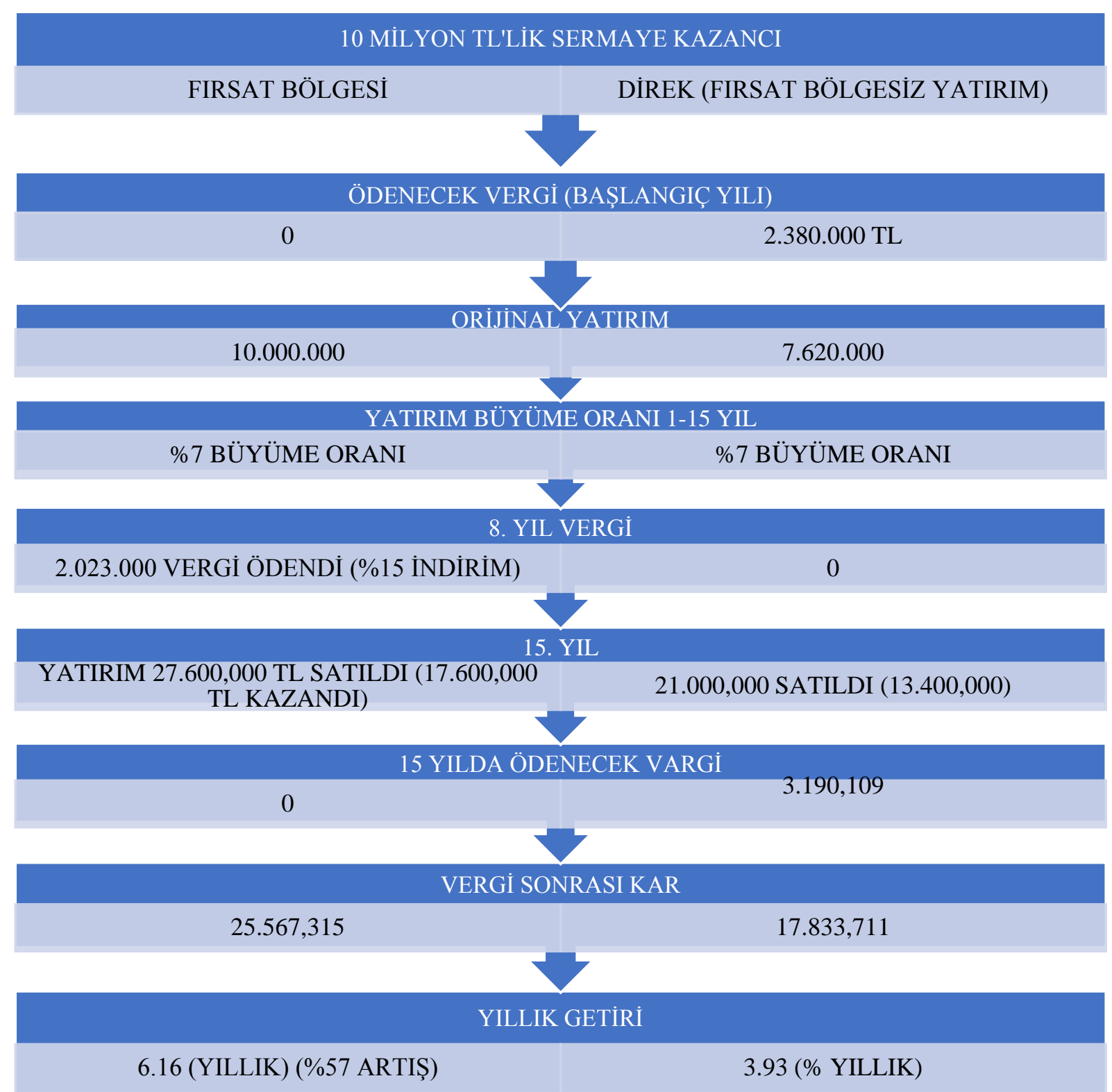




\section{YATIRIM ŞARTLARI}

Yatırım yapılan işletmenin gelirinin \%50'si fırsat bölgesinden elde etmelidir. Gayrimenkul sektöründe bunu kanıtlamak kolayken, sanayi üretiminde ve e-ticarette belirsizlik taşımaktadır. Bu kural özellikle e-ticaretin gelişmesi sebebiyle işletme çalışanlarının çalışma vakitlerinin \%50'si kadarının firsat bölgesinde olması şartıyla yeni kanunda esnetildi (O’brien, 2018).

Yatırımcı, mevcut sermaye kazancı elde ettikten 180 gün içinde fırsat bölgesine doğrudan veya fona yatırım yapması gereklidir.

Uzun dönemli (bir yıldan fazla) sermaye kazançları yasa kapsamındadır. Kısa dönemli sermaye kazançları (bir yıldan az) yasa kapsamında değildir.

Fon kurulduktan sonra 31 ay içinde yatırım yapmalıdır. Ama vergisel avantajları baştan itibaren sağlanmaktadır.

Fonların yatırımlarının \%90'ını fırsat bölgelerinde olmalıdır. Yatırım konusu iş kurmaktan finansal yatırıma kadar geniş tutulmaktadır.

\section{VAKIFLARIN VE SIVIL TOPLUM ÖRGÜTLERININ ANAHTAR ROLÜ}

Hayırseverlerin fırsat bölgelerinin ekonomik ve sosyal etkilerini kalkındırmakta yardımcı olmalarında kritik bir rol oynadığı açıktır. Vakıflar (ve sivil toplum örgütleri) sorunlu konuları ve yöreleri kalkındırmak için kurulmuşlardır. Farklı oyuncuları (yatırımcılar, sivil toplum örgütleri, yerel yönetimler gibi) bir araya getirmek için gereken prestije ve kapasiteye sahiptirler. Ayrıca sosyal girişimcilere ve diğer yerel kurumlara yatırım yapmak için ihtiyaç duydukları sermayeye sahiplerdir. Vakıflar kâr amaçlı olmadıklarından daha fazla riske tahammül etmektedirler ve uzun vadeli bir bakış açısına sahip olmaktadırlar (Katz, 2019).

Fırsat Bölgesi yasasıyla, sivil toplum örgütlerinin ve vakıfların oynayabilecekler önemli roller şunlar olmakta:

Koordinasyon: Yoksul bir mahalleyi geliştirmek için herkesi bir araya toplayabilmektedirler. Hayırseverleri, kamu yönetimleri, işletmeleri ve diğer alanlarda liderleri içeren çabaları koordine ederek şehirlerin başarı için örgütlenmesine yardımcı olmaktadırlar. Yatırımcıların fırsat bölgelerinin potansiyelini anlamalarına yardımcı olabilirler ve bölgede neye katkıda bulunabilecekleri ve ihtiyaç duyulanlar konusunda yatırımcıları yönlendirebilmekteler (Katz, 2019).

Bölgenin varlıklarının belirlenmesi: Vakıflar, fırsat bölgeleri için güçlü yatırım olanakları geliştirmek için gereken çalışmaları finanse etmekteler. Finansman güç bu bölgelerin rekabet avantajlarını iletmelerini, yerel ortaklıkları teşvik etmelerini, kamu ve özel sermaye için hazır olan sağlam projeleri tespit etmelerini sağlayacaktır. Vakıflar dış uzmanlık, özel veri toplama ve analizleri ile basılı ve web tabanlı pazarlama materyallerinin masraflarını ödeyebilmekteler (Katz, 2019).

Piyasalar oluşturulması: Özel veya hayırsever bir yatırımcı için projenin destekleyebileceği borç miktarı ile mevcut öz kaynak arasındaki açığı doldurmaktalar. Finans dünyasında imtiyazlı sermaye olarak bilinen bu rol, fırsat bölgesinde projelerde kritik öneme sahip olmaktadır. Geleneksel hibelerden ziyade, bu etki yatırımların finansal ve sosyal olarak geri dönüş sağlayabilmekte ve bir vakfin genel 
yatırım stratejisinin yanı sıra programla ilgili bir yatırım planının önemli bir parçası olabilmekteler. Örneğin yeni kurulacak firsat bölgesi fonuna sermaye koyabilmekteler (Katz, 2019).

Yerel sakinleri güçlendirme: Fırsat bölgelerinde yaşayan sakinlerin tercihlerini ifade etmelerine, becerilerini edinmelerine, iş kurmalarına ve mahalledeki yaşam kalitesini iyileştirmelerine yardımcı olabilmekteler.

Kurumları geliştirme: Birçok toplulukta yerel yönetimler, yerel ekonomiyi dönüştürebilecek karmaşık programlar tasarlama, finanse etme, sunma kapasitesine veya profesyonel uzmanlığına sahip değildirler. Vakıflar bu eksikliği giderebilmektedirler.

İnovasyonu teşvik etme: Kent sakinlerinin çığır açan fikirler geliştirmek veya yatırım stratejilerini desteklemek için inovasyonu teşvik etme hibeleri ve diğer mekanizmaları kurabilmekteler (Katz, 2019).

Bilgi paylaşımı: Bölgenin nüfus, coğrafya, ekonomik, sosyal yapısıyla detaylı bilgilerin paylaşımın sağlanmasıdır. Örneğin bir turizm hareketliliği mevcutsa, yıllara göre artışlar, aylık dağılımlarına kadar detaylı bilgilerin sağlanması ve yayılmasına öncelik edilebilmekteler. Nüfusun harcama kalemleri (elektrik tüketiminden gıda tüketimine kadar), ortalama geliri, gelir dağılımı gibi sadece o bölgeye ait bilgiler paylaşılabilmekteler (Katz, 2019).

\section{FONLARIN ROLÜ}

Yatırımcılar, yatırım risklerini dağıtmak için fonlar oluşturmaktadır. Fırsat bölgeleri fonları, fırsat bölgelerine sermayelerinin en az yüzde 90'ını yatırım yapan özel sektör yatırım araçlarıdır. Fon modeli geniş bir yatırımcı kitlesinin kaynaklarını fırsat alanlarında bir araya getirmesini sağlayacak ve bu sayede fırsat alanlara yapılacak yatırımların ölçeğini artırmaktadır.

Fırsat fonu statüsü kazanmak için:

- ABD hazine bakanlığı tarafından onaylanmış olmalıdır.

- Nitelikli fırsat bölgesi özelliğine yatırım yapmak için bir kurum veya ortaklık olarak düzenlenmelidir.

- Nitelikli bir fırsat bölgesi işinde yeni çıkarılan hisse senedi, ortaklık çıkarları veya ticari mülkü içeren varlıklarının en az yüzde 90'ını elinde bulundurmalıdır.

- Yatırımlar, fırsat bölgesindeki yer alan işletmelerdeki, gayrimenkul ve ticari varlıklardaki öz kaynak yatırımlarıyla sınırlı olmalıdır. Krediler ve diğer vergi teşvikleri için uygun değildir. Fırsat fonu, gayrimenkul yatırımları için rehabilitasyon şartına tabidir (Hooper, 2019).

\section{TÜRKIYYE'DEKİ TEŞVİKLERE GÖRE FARKI NEDİR?}

Türkiye'deki teşviklere göre farkı aşağıda sıralanmaktadır:

1. Türkiye'deki teşvikler iller bazındadır. Bir il ya tamamıyla teşvik bölgesindedir ya da değildir. Bu durumda varlıklı bir ilde bulunan fakir bölgeler faydalanamamaktadırlar. 
2. Türkiye’deki uygulamada yatırım yapıldığında vergi teşvik imkânı sağlanmaktadır. Mevcut olan bir vergi yükümlülüğüne yönelik bir teşvik yoktur. A.B.D. yeni teşvik yasasının en önemli hususlarından faydanın hemen görebilme imkânı sağlanmasıdır. Davranışsal iktisadın vurguladığı gibi sonradan elde edilecek faydalar yüksek oranla iskonto edilmektedir. Yasa sadece gelecekte elde edilecek kazançları vergisiz hale getirmemekte ama aynı zamanda mevcut vergiyi öteleme ve düşürme imkânı vermiştir. Yatırımcı psikolojik olarak ilk günden karlı hissetmiştir. Ayrıca vergi yükünden dolayı sermaye gelirini elde etmekten çekince gösteren yatırımcılara yatırımlarını nakde dönme imkânı sağlamıştır.

3. Teşvik bölgesindeki teşvikten faydalanmak için aktif olarak yatırım yapılması gerekmektedir. Türkiye'de bunu bir fon üzerinden pasif yatırımcı olarak gerçekleştirilememektedir. A.B.D.'de fonun yatırımının en az \%90'nunun firsat bölgesinde olması şartıyla teşviklerden faydalanılmaktadır (U.S. Treasury, 2018).

4. Türkiye'de teşvik kapsamına giren illerde her ekonomik faaliyet vergi indirimine konu olmamaktadır. Ekonomik faaliyetin ilde belli noktalarda (organize sanayi bölgesinde) ve belli sektörlerde (tarım) olmalıdır. A.B.D.'de yasa bunu konu ve miktar sıralaması getirmemiştir. Bu aşamada bütün hedef sermayeyi ve sermayedarı fırsat bölgesine sokmaktır.

\section{ELEŞTİRILER}

Amerikan firsat bölgesi yasasına karşı yapılan eleştiriler aşağıdadır:

1. Yatırımlar konusunda ayırım yapılmamasından dolayı, ağılıklı olarak yüksek gelir yaratan startuplar yerine gayrimenkul sektörüne ağırlıklı büyüme olmaktadır (Tankersley, 2019).

2. Gayrimenkul ağırlıklı yatırım daimî iş imkanını azaltmaktadır (Tankersleyi 2019).

3. 2017'de kabul edilen ve 2019'da yenilenen kanunun getirmiş olduğu ekonomik ve sosyal veri azdır. Performansı ölçülememektedir (Tankersley, 2019).

4. Gayrimenkullerin değerlenmesiyle yörede yaşayanların gelirleriyle ulaşamadıkları bir fiyata yükselmektedir. Göç etmek zorunda kalmaktadırlar.

5. Teşvik kapsamındaki firsat bölgelerinin tamamı fakir yöreler değildir. Eyalet valilerinin kararlarıyla bazı gelişmekte olan yörelerde bu kapsama konmuştur. Kalkınmamış bölgelerin kalkınmalarına yardımcı olmak için mi yoksa zenginlerin vergisel imkanlar getirmek için mi tasarlandığı sorusu akla gelmektedir (Mui, 2018).

Amerikan kongresi, fırsat bölgelerindeki teşviklerin etkinliğinin ölçülmesi için vergi idaresinden vergi indirimi alan yatırımcılardan veri toplamalarını, yatırımlarının ekonomik koşullarını nasıl değiştirdiğini göstermesini isteyen yasalar getirmeyi planlanmaktadır (Tankersley, 2019). Vergi dairesi kaç fonun kurulduğu, hangi varlıklara sahip olduklarına, kaç iş yaratıldığına ve yoksulluk seviyelerinin nasıl değiştiğine ilişkin verileri derleyecektir. 


\section{SONUÇ VE TARTIŞMA}

Fırsat bölgesi yasası iki gruba odaklanmaktadır: büyük yatırım karı olan sermayedarlar ve düşük gelirli mahallelerdeki topluluklar (O’Brien, 2018).

Temel olarak, federal hükümet yatırımcının sermaye kazançlarını fırsat fonları üzerinden 10 yıl boyunca fırsat bölgesi projelerinden birine yatırım yapmak için kullanmasına izin vermektedir. 10 yıl sonra, yatırımcı aktifin değerinin yükselmesinden dolayı herhangi bir sermaye kazancı vergisi ödememektedir. Ayıca federal hükümet ödenmesi zorunlu mevcut sermaye kazanç vergisini 7 yıl sonra $\% 15$ indirimle almaktadır.

Amerikan gelir vergisinde sermaye kazançları önemli yer tutmaktadır. Sadece fonlarda vergilendirilmemiş 6.1 trilyon dolar potansiyel sermaye kazancı mevcuttur. Türkiye'de fonlarda vergi stopaj oran $1 \% 0-\% 10$ arasında değişmektedir. Gelir vergisi beyannamesine tabii değildirler. Elbette bunu stopaj veya gelir vergisi olarak almak sermaye kazancına vergi avantajı sağlamaya engel değildir. Borsada hisse satış gelirleri de vergiden muaftır. 5 yıldan az tutulmuş emlak satışından elde edilen gelirlerin vergisel yükümlülükleri vardır. Temelde, Türk vergi sisteminin ağırlıklı olarak dolaylı vergilerden oluşmasından (\%70) dolayı bu sistemin çalışması için tüm dolaysız vergileri A.B.D. vergi teşvikinde olduğu gibi değerlendirmek gereklidir. Yani gelirler ve kurumlar vergisi ödeyeceklerin (sermayedarların stopaj vergileri dahil) belli bir yüzdesi için verginin ötelenmesi, teşvik yörelerine yatırım yapan fonların vergiden muaf olması ve fon yatırımcısından sermaye kazanç vergisinden muaf olması sağlanmalıdır. Amerika'daki 10 yıl bekleme süresi, Türk yatırımcısının daha kısa vadeli düşünme eğiliminden dolayı, bekleme süresi kısaltılabilir. Vergi ödemelerinin 7 yıl sonraya sarkması, yüksek enflasyonlu bir ülke olan Türkiye için ciddi vergi kaybına yol açmaktadır. Öte taraftan yatırımcı için büyük bir kazançtır. Özel sermaye kuruluşları ve devlet tarafından sağlanan maddi imkanlar ancak sivil toplum örgütleri, yerel yönetimler, vakıflar, girişimciler ile birlikte hareket edildiği takdirde olmaktadır.

Kalkınmakta olan yörelere yatırım yapmak aynı zamanda bir hayırseverlik faaliyetidir. Bu hayırseverlik yönünde vakıf benzeri sivil toplum örgütlerine hem de hayırsever vatandaşlara önemli roller düşmektedir. 


\section{KAYNAKÇA}

Çiloğlu, İ., (2000). Teşvik politikasının yönlendirme gücü. Hazine Dergisi, 13, Ocak.

Dağ, M. ve Çelik, M. (2018). Yatırım teşvikleri nedir? Kavram ve kapsamı üzerine bir değerlendirme. BEÜ SBE Dergisi,7 (2), 863-875

Davison L., Buhayar N. (2019). Trump's opportunity zone rules deliver on investors' wish list.. wealth management magazine, Retrieved May 10, 2019, from https://www.wealthmanagement.com/high-net-worth/trumps-opportunity-zone-rules-deliver-investorswish-list

Investreal (2019). What are opportunity zones? Retrieved May, 9, 2019, from https://www.accountingtoday.com/news/opportunity-zone-rules-aim-to-spur-further-business-andreal-estate investment?utm_content=buffer42bcf\&utm_medium=social\&utm_source=twitter.com\&utm_campaig n=buffer

Gülmez, M . ve Yalman, İ. N; (2010), Yatırım teşviklerinin bölgesel kalkınmaya etkileri, Atatürk Üniversitesi İ̈BF Dergisi, 24 (2), 235-257.

Hooper, A. (2019). Opportunity zones explained. Retrieved May, 7, 2019, from https://www.wealthmanagement.com/alternative-investments/opportunity-zones-explained

Katz, B., (2019). How philanthropy can ensure opportunity zones ensure widespread economic renewal. Retrieved May, 9, 2019, from https://www.philanthropy.com/article/Opportunity-ZonesCould-Become/246177?key=GCZRFFWJmdWfHIIYJmst8AtbvvHiT74-GtevgtGtii9jJniZ1SakzczEsxdV7LidnRUaEp4QUpFYUR5eEZqTmk4QllZb2lvU2ZPcGJ5NWtlM1RT NXU1d1dtbw.

Looney, A. (2018). The early result of states' opportunity zones are promising. brookings institute. Retrieved, May, 5, 2019, from https://www.brookings.edu/research/the-early-results-ofstates-opportunity-zones-are-promising-but-theres-still-room-for-improvement/

Nitti T. (2019).IRS releases latest round of opportunity zone regulations: where do we stand now? Retreived, May, 3, 2019, from https://www.forbes.com/sites/anthonynitti/2019/04/22/irs-releaseslatest-round-of-opportunity-zone-regulations-where-do-we-standnow/?utm_source=dlvr.it\&utm_medium=twitter\#6a363a3b2772

O’Brien Sarah (2018). Heard the buzz about opportunity zone funds? Erişim Tarihi: 2 Mayıs 2019, https://www.cnbc.com/2018/10/31/heard-the-buzz-about-opportunity-zone-funds-heres-theskinny.html?_source=twitter\%7Cmain

Perlman, E. (2019). How investors can ensure their opportunity zone investment is a smart deal, Forbes, Erişim Tarihi: 2, Mayı, https://www.forbes.com/sites/forbesrealestatecouncil/2019/01/03/how-investors-can-ensure-theiropportunity-zone-investment-is-a-smart-deal/\#7574bd541423 
Özker, A. ve Biniş, M . (2010). Vergi uygulamalarında bölgesel kalkınma hedefleri ve bölgesel mali teşvikler açısından değerlendirilmesi. Sosyal Ekonomik Araştırmalar Dergisi, 10 (19), 491-508.

Tankersley, J. (2019) Treasury issues rules on tax breaks for opportunity zones. Erişim Tarihi: 7 Mayıs 2019, https://www.nytimes.com/2019/04/17/business/economy/opportunity-zones-treasuryregulations.html?action=click\&module=Well\&pgtype=Homepage\&section=Business

Thomas, B. (2019). Welcome to the wonderful land of OZ. https://www.forbes.com/sites/bradthomas/2019/04/20/welcome-to-the-wonderful-land-ofoz/\#d64fd1d7d05c

Treasury (2018). Treasury, IRS announce first round of opportunity zones designations for 18 states. https://home.treasury.gov/news/press-releases/sm0341

Ünsaldı, M. (2006). Devlet Teşvikleri ve Bölgesel Gelişmişlik Farklılıkları Üzerine Etkileri. Elazığ: Fırat Üniversitesi Doğu Anadolu Bölge Araştırma ve Uygulama Merkezi (DAP Araştırmaları).

Yayar, R, Demir, Y . (2015). Bölgesel kalkınmave yatırım teşvikleri: Tokat ilinde bir uygulama. Erciyes Üniversitesi İktisadi ve İdari Bilimler Fakültesi Dergisi, 0 (39), 119-146.

Ylan, M. (2018). Investors can get big tax breaks if they invest in 'opportunity zones' under new Treasury rules. Erişim Tarihi: 1 Mayıs 2019, https://www.cnbc.com/2018/10/19/investors-can-gettax-breaks-for-investing-in-opportunity-zones-treasury.html 